\title{
The Coordination Chemistry of DNA Nucleosides on Gold Nanoparticles as a Probe by SERS
}

\author{
Nak Han Jang \\ Department of Chemistry Education, Seoul Kational Lniversity Seoul 151-7+2, Korea \\ Received November 1, 2002
}

\begin{abstract}
The DNA nucleosides ( $\mathrm{dA}, \mathrm{dC}, \mathrm{dG}, \mathrm{dT}$ ) bound to gold nanoparticles $(\sim 13 \mathrm{~nm})$ in aqueous solution has been studied as a probe by the SERS and their coordination structures have been proposed on the basis of them. According to UV-Visible absorption of gold nanoparticles after modifying with DNA nucleosides. the rates of absorption of $\mathrm{dA}$. $\mathrm{dC}$, and $\mathrm{dG}$ were much faster than that of $\mathrm{dT}$ as monitored by the aggregation kinetics at 700 $\mathrm{nm}$. These data indicated that the nucleosides $\mathrm{dA}$. $\mathrm{dC}$, and $\mathrm{dG}$ had a higher affinity for the gold nanoparticles surface than nucleoside dT. As the result of SERS spectra, the binding modes of each of the nucleosides on gold nanoparticles have been assigned. A dA binds to gold nanoparticles via a N(7) nitrogen atom of the inudazole ring, which the $\mathrm{C}(6)-\mathrm{NH}_{2}$ group also participates in the coordination process. In the case of $\mathrm{dC}$. it binds to the gold surface via a $\mathrm{N}(3)$ nitrogen atom of the pyrimidine ring with a partial contribution from the oxygen of $\mathrm{C}(2)=\mathrm{O}$ group. A coordination of $\mathrm{dG}$ to the gold surfaces is also proposed. Although the dG has the two different nitrogens of a pyrimidine ring and the amino group, the $\mathrm{N}(1)$ nitrogen atom of a pyrimidine ring has a higher affinity after the hydrogen migrates to the amino group. Conversely, dT binds wia the oxygen of the $\mathrm{C}(4)=\mathrm{O}$ group of the pyrimidine ring. Accordingly. these data suggest that the nitrogen atom of the imidazole or the pyrimidine ring in the DNA nucleosides will bind more fast to the gold nanoparticles surfaces than the oxygen atom of the carbonyl group.
\end{abstract}

Key Words : DNA mucleosides. SERS. Coordination. Gold nanoparticles

\section{Introduction}

Significant efforts have focused on binding oligonucleosides to metal surfaces and colloids for the variety of important fundamental studies and applications. including the study of electron transfer through $\mathrm{DNA}^{\mathrm{l}}$ and the development of novel DNA detection teclunologies. ' Recently: Mirkin and coworkers reported a new DNA detection teclunology based on the sequence-specific interactions of DNA-modified gold nanoparticles probes with a target DNA analy te. ${ }^{3-5}$ Because of these recent advances in using DNA to build a variety of functional materials ${ }^{6}$ an understanding of how DNA and its building blocks interact with surfaces on the molecular level would be crucial. However. only a few studies have generated pertinent structural information regarding the binding and conformation of oligonucleosides and their building blocks on gold surfaces. ${ }^{7.8}$ In order to optimize DNA detection and other technologies based on DNA binding to metal surfaces. it is of utmost importance to understand how DNA and its building blocks interact with gold nanoparticles and other surfaces. Ultimately, it is envisioned that studies of $\mathrm{DNA} /$ surface interactions would be helpful for the design of the DNA-modified gold nanoparticles probes that can target DNA sequences with optimal sequence specificity and selectivity as well as the nanoparticles stability and reactivity.

Over the past 20-years. surface-enhanced Raman scattering (SERS) ${ }^{4}$ has had a great impact on characterizing DNA

"Corresponding Author. E-mail: nlijb64annizzou. edu and other biological molecules on metal surfaces since the inherently weak Raman signal are enhanced and the high fluorescence is quenched. A number of SERS spectra of DNA and RNA bases have been extensively studied on both electrode and colloid surfaces. ${ }^{10-18}$ However. the exact coordination structures of the DNA nucleoside bases on metal surfaces have not been reported previously. In order to elucidate the coordination structures of the DNA nucleoside bases on gold nanoparticles. it is be necessary to assign precise frequencies to each SERS band.

The SERS study of the DNA nucleosides on gold surface is of particular interest. since they possess many different functionalities that could potentially bind to the gold surface. such as the sy'stem of the pyrimidine ring the $\mathrm{C}=\mathrm{O}$ functionality and the lone-pair electrons of the heterocyclic and exocyclic nitrogen atoms (see in Figure 1). Since some of these functionalities participates in Watson-Crick basepairing. it is essential that the binding modes of each base is understood so that the DNA-modified gold nanoparticles can be optimized for binding complementary DNA sequences.

In the present paper. I report the UV-Vis and SERS spectra of 2'-Deosyadenosine (dA). 2'-Deosycytidine (dC). 2'Deoxyguanosine $(\mathrm{dG})$ and 2'-Deoxythymidine $(\mathrm{dT})$ on gold nanoparticles. The binding affinity of each base for the gold nanoparticle surfaces is discussed and an interpretation in terms of normal mode assignments of the Raman spectra is presented. The SERS data are also compared with the normal Raman spectra in solid and in aqueous solution. Based on this study, the coordination structures of the DNA nucleosides on gold surfaces are proposed. 
(a)<smiles>[R]n1cnc2c(N)ncnc21</smiles>

(c)<smiles>[R]n1cnc2c(=O)[nH]c(N)nc21</smiles>

(b)<smiles>[R]n1ccc(N)nc1=O</smiles>

(d)<smiles>[R]n1cc(C)c(=O)[nH]c1=O</smiles>

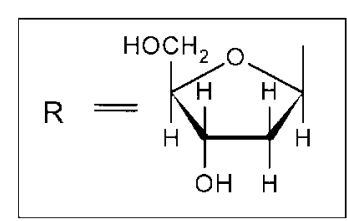

Figure 1. The structure of DNA nucleosides and the numbering of the purine, pyrimidine ring used in expressing the normal modes of vibrations: (a) $2^{\prime}$-Deoxyadenosine (dA), (b) $2^{\prime}$-Deosycytidine (dC), (c) $2^{\prime}$-Deosyguanosine (dG), and (d) $2^{\prime}$-Deosy thymidine (dT).

\section{Experimental Section}

Preparation of Gold Nanoparticles. Approximately 13 num diameter gold particles were prepared by the citrate reduction of $\mathrm{HAuCl}_{4}$ as described previously $\mathrm{An} 0.1 \mathrm{~mL}$ of $4 \%(w / v) \mathrm{HAuCl}_{4}$ solution was added to a reflux of $40 \mathrm{~mL}$ of nanopure water while stirring and then $1 \mathrm{~mL}$ of $1 \%(\mathrm{w} / \mathrm{s})$ trisodium citrate solution was quickly added drop by drop while stirring. which resulted in a change in solution color from pale yellow to deep red. After the color change. the resulting mixture was boiled for additional five minutes. allowed to cool to room temperature and the final color of solution obtained was raspberry-red. Gold naonoprticles in $\mathrm{D}_{3} \mathrm{O}$ were made in exactly the same fashion. substituting $\mathrm{D}_{2} \mathrm{O}(99.9 \%)$ for water. A týpical solution of $13 \mathrm{~nm}$ diameter gold particles exhibited a characteristic surface plasmon absorption maximum at $520 \mathrm{~mm}$. Electronic absorption spectra were recorded on a Hewlett-Packard 8452A diode array spectrophotometer.

Preparation of Materials. $\mathrm{HAuCl}_{4} \cdot 3 \mathrm{H}_{2} \mathrm{O}$ and Trisodium Citrate were purchased from Aldrich Chemical Company. 2'-Deoxyadenosine (dA) and 2'-Deoxycytidine $(\mathrm{dC})$ were purchased from Sigma. 2'-Deoxyguanosine (dG) from Merck and $2^{\prime}$-Deoxỵthỵmidine (dT) from American BioNuclear. respectively. To assure the similar structure of $\mathrm{dG}^{2} 2^{\prime}$ DeoxyInosine (dI) were also purchased from Sigma. All reagents were used without further purification. N-Deuterated species of $\mathrm{dA}, \mathrm{dC} . \mathrm{dG}$. and $\mathrm{dT}$ were prepared by dissolving the molecules in $\mathrm{D}_{2} \mathrm{O}(99.9 \%$. Aldrich) to undergo isotopic exchange and evaporating to dry. This procedure was repeated three times and the deuterated nucleosides were taken by
NMR spectroscopy (Gemini 300. Varian) to if deuterium was changed or not. For all experiments. Nanopure $\mathrm{H}_{2} \mathrm{O}$ (18.1 MS) purified using a NANOpure ultra water șystem (Barnstead) was used. All glasswares were cleaned in aqua regia (3 parts $\mathrm{HCl} .1$ parts $\mathrm{HNO}_{3}$ ), rinsed with nanopure $\mathrm{H}_{2} \mathrm{O}$, and then dried in oven prior to use.

Stock solutions of $1 \times 10^{-4} \mathrm{M}$ concentration for DNA nucleosides were prepared by using the neutral water. The adsorbate was introduced in the nanoparticles by adding one drop (about $0.03 \mathrm{~mL}$ ) of the above stock solutions to approximately $1 \mathrm{~mL}$ of gold colloid solution. A few drop of $3 \%$ poly (vinylpyrrolidone) (PVP. MW 10000) was added to the sample as stabilizer. preventing further aggregation and eventual flocculation of the colloid. The overall concentration of each DNA nucleoside was about $3 \times 10^{-i} \mathrm{M}$ in nucleoside/Au sample. After modifying with the DNA nucleosides. the aggregation of particles is monitored by UV-Visible spectroscopy (Hewlett-Packard 8452A diode array').

Raman Spectroscopy. $\mathrm{Ar}^{+}$laser (Innova 400. Coherent) was used for solution spectra with $200 \mathrm{~mW}$ laser power at $\lambda_{\mathrm{ex}}=488 \mathrm{~nm}$. Raman spectra of a solid sample were achieved by using FT-Raman spectrometer (BioRad) equipped with $1064 \mathrm{um}$ Nd:YAG laser (Spectra Physics) and the laser power used was $200 \mathrm{~mW}$ at sample position. For the SERS spectra. ${ }^{20}$ the multiline $\mathrm{Ar}^{-}$laser (Innova 400. Coherent) was used to pump a Spectra Physics Tsunami model locked Ti:Sapphire prism to obtain $\lambda_{\mathrm{ex}}=710 \mathrm{~mm}$ and the laser power used was also about $200 \mathrm{~mW}$ at sample position. A band pass filter (Oriel Corporation. Stratford. CT) centered at $710 \mathrm{~nm}$ with a $10 \mathrm{~mm}$ range was utilized for removing extra lines. Spectra were recorded at $\lambda_{\mathrm{ex}}=488 \mathrm{~nm}$ and $\lambda_{\mathrm{ex}}=$ $710 \mathrm{~nm}$ using a SPEX Model 1877 Triplemate multichannel monochromator equipped with 600 groove/1um grating blazed at $710 \mathrm{~nm}$ in the filter stage, 1200 groove/mun gratings in the spectrograph stage. and a SPEX Spectrum One chargecoupled device(CCD) detector. The Raman cell used was a 5 mm NMR tube (Ace Glass) and was spun to maintain sample homogeneity and to prevent localized heating. The angle of an incidence of the laser excitation source was $\sim 45^{\circ}$ with respect to the normal surface and Raman scattered light was collected parallel to the surface normally. All Raman frequencies were calibrated by comparing with the measured $\mathrm{CCl}_{4}$ frequency $\left(217,314,459 \mathrm{~cm}^{-1}\right)$.

\section{Results and Discussion}

My initial goal was focused on determining the binding affinity of each deoxynucleoside for the gold nanoparticle surfaces. The surface plasmon resonance of the gold nanoparticles. which is sensitive to particle aggregation, offered a simple spectroscopic tag for monitoring adsorption of the neutrally charged deoxynucleoside onto the nanoparticle surface. Accordingly: UV-Vis spectroscopy was used to monitor the binding affinity of each DNA nucleoside to 13 nu diameter gold nanoparticles in Figure 2. The UV-Vis spectrum (spectrum a) of $13 \mathrm{~nm}$ diameter gold nanoparticles 

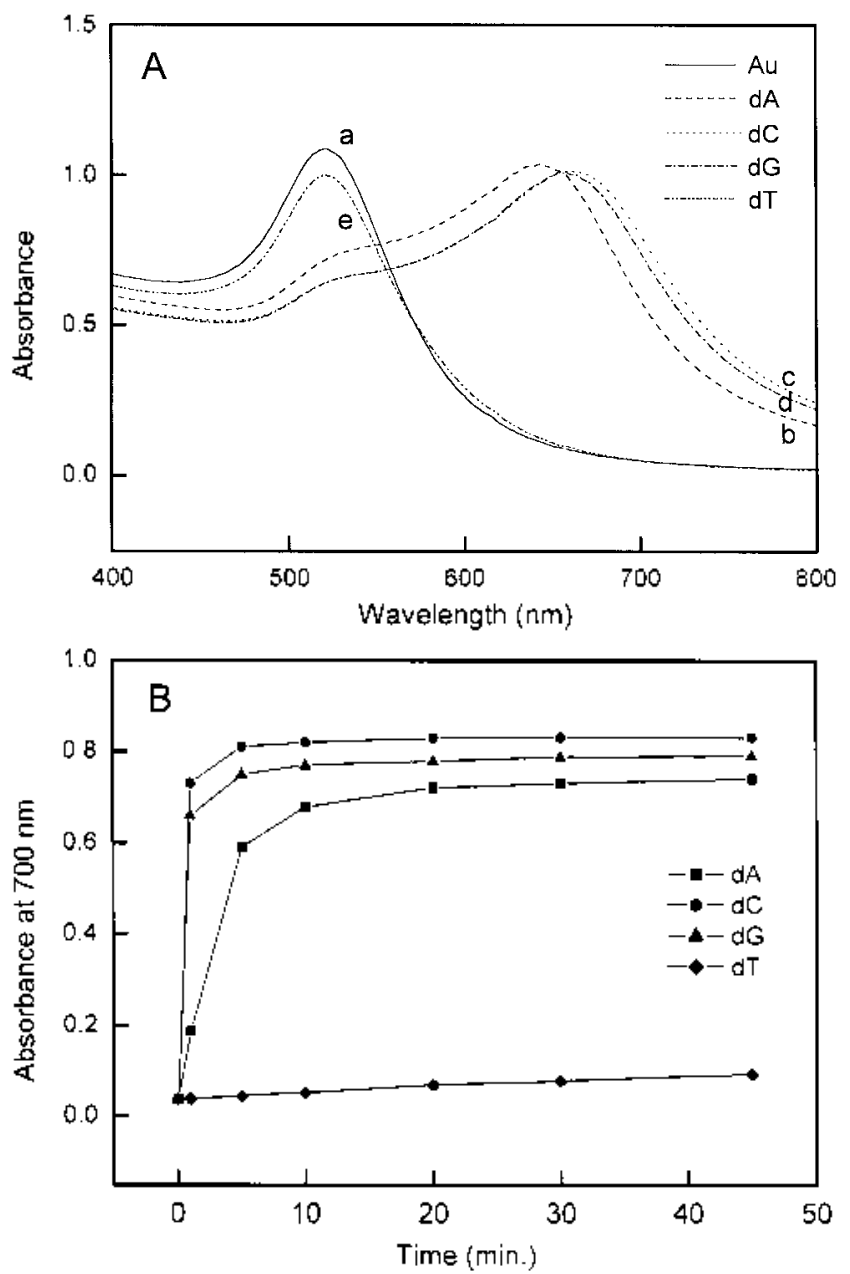

Figure 2. UV-Visible absorption spectra of a gold nanoparticles: (A) (a) in the absence of adsorbate and 5 minutes after modifying with DNA nucleosides (b) $\mathrm{dA}$ (c) $\mathrm{dC}$ (d) $\mathrm{dG}$, and (e) $\mathrm{dT}$ : (B) depending on time after modification at $700 \mathrm{~nm}$ for $(\mathrm{f}) \mathrm{dA},(\mathrm{g}) \mathrm{dC}$, (h) $\mathrm{dG}$, and (i) dT.

$(\approx 20 \mathrm{nM})$ is shown for reference. which has a maximum at about $520 \mathrm{~mm}$ in Figure 2A. Spectra b to e in Figure 2A show the changes in the plasmon band when each DNA nucleoside $(3 \mu \mathrm{M})$ was added to a $20 \mathrm{nM}$ solution of $13 \mathrm{~nm}$ diameter gold nanoparicles. At this concentration. all of the deoxynucleosides except dT exhibited major changes in the plasmon region after a minute. For a better comparison. the adsorption kinetics of the nucleosides was monitored by growth of the plasmon band at $700 \mathrm{~nm}{ }^{5}$ As expected. the deoxynucleosides $\mathrm{dA} . \mathrm{dC}$. and $\mathrm{dG}$ exhibited much faster growth kinetics than that of dT under the same conditions (Figure 2B). This indicates that the nucleosides $\mathrm{dA}, \mathrm{dC}$. and $\mathrm{dG}$ have a higher binding affinity for the gold nanoparticles surface that that of $\mathrm{dT}$. This result was not surprising when considered that $\mathrm{dT}$ is the only base that does not contain an exocyclic amine moiety or deprotonated heterocyclic nitrogen. However. at this stage it is unclear which nucleoside functionalities play the most important role in dictating nucleoside binding to the gold nanoparticle surfaces. To probe the coordination chemistry between the nucleosides and the gold nanoparticles. SERS spectra were performed on each of the gold nanoparticles/deoxynucleoside aggregates. It is important to note that the complex time behavior observed for the adsorption of deoxynucleoside onto gold nanoparticles leads to SERS spectra being recorded at various times for the different deoxynucleoside. since sufficient aggregation is required to produce SERS active molecules on the surface (see Experimental)

Assignments and Coordination Structures. Figure 3-6 show SERS spectra of solution's $\mathrm{dA} . \mathrm{dC}, \mathrm{dG}$ and $\mathrm{dT}$ on gold nanoparticles in aquous solution at $\mathrm{pH} 7$ as compared to the FT-Raman of solid. the normal Raman in solution and the deuterated SERS spectra. All of the Raman bands have been attributed to vibrational modes of the high polarizable aromatic base functionalities. It is noted that SERS bands associated with sugar vibrations are hardly observed due to the presence of the weakly polarizable single bonds associated with the sugar moiety. which supports the conclusion that this portion of the molecule does not directly bind to the gold surface.

Assignments of SERS band frequencies for the DNA nucleosides were determined by comparing the frequencies of the observed Raman data with the spectra obtained previously for the bases and nucleosides using other methods ${ }^{0-18.21}$ and by using the vibrational data of references." These tentative assignments for the SERS bands are listed in Table 1 for comparison the measured normal and FT-Raman frequencies in solution and in the solid.

Nucleosides contain two characteristic ligating regions which are capable of metal binding: (1) the heterocylic ring $\mathrm{N}$ atoms and the exocylic functional groups of the purine and pyrimidine bases. and (2) the hydrosy $\mathrm{O}$ atoms of the deosyribose sugar moiety: For nucleoside-transition metal. $\mathrm{X}$-ray structure studies ${ }^{23}$ have shown these two modes of binding to predominate. All the binary mononucleoside of an adenosine (dAMP), and guanine (dGMP) were covalently bonded to $\mathrm{N}(7)$ of the purine base. When DNA nucleosides bind to the gold nanoparticles. their binding sites could potentially be much different from that of transitional metal complex.

Until now in studying the SERS spectra of mononucleosides at $\mathrm{Ag}$ electrode. ${ }^{14 \mathrm{~b}}$ it has been reported that the spectra of cytosine (dCMP), guanine (dGMP) and thymine (dTMP) or uracil (dUMP) could not be obtained except the mononucleoside of adenine (dAMP). It means that others except dAMP do not adsorb to the Ag surface, revealing the absence of an SERS signal in their measurements on mononucleoside. It can be concluded that only in the case of dAMP the adsorption is not hampered by the sugarphosphate group. In other words. the presence of the sugarphosphate group at the N(l)-position of cytosine and thymine and at the $\mathrm{N}(9)$-position of guanine prevents the direct interaction of the base portion of these nucleosides to the silver surface.

1. IA. SERS spectra of dA on gold nanoparticles is plotted at Figure 3 and summarized in Table 1. Figure $3 \mathrm{C}$ shows the strong. characteristic SERS bands for $\mathrm{dA}$ at 728.1320 . and 
Table 1. Assignnents of Raman spectra for DNA nucleosides

\begin{tabular}{|c|c|c|c|c|c|c|c|c|c|c|c|c|c|}
\hline & dA & & & $\mathrm{dC}$ & & & dG & & & dT & & Tentat & ive A sianment \\
\hline Solid ${ }^{a}$ & Liquid ${ }^{5}$ & SERS $^{c}$ & Solid $^{\sigma}$ & Liquid ${ }^{b}$ & SERS ${ }^{c}$ & Solida & Liquid $^{b}$ & SERS & Solid ${ }^{a}$ & Liquid $^{b}$ & SERS ${ }^{\prime}$ & Iental & 1te Assignment \\
\hline 1687 & & 1657 & & & & & & & & & & $\beta_{2}\left(\mathrm{NH}_{2}\right)$ & $\mathrm{NH}_{2}$ Scissoring \\
\hline & & & 1664 & 1662 & 1639 & 1687 & & 1642 & 1664 & 1665 & 1647 & $v_{s}(\mathrm{C}=\mathrm{O})$ & $\mathrm{C}=\mathrm{O}$ Stretching \\
\hline 1614 & & 1594 & 1618 & 1605 & & & & & & & & $\delta\left(\mathrm{NH}_{2}\right)$ & $\mathrm{NH}_{2}$ Detomation \\
\hline 1572 & 1581 & 1551 & 1568 & & 1572 & 1579 & 1580 & 1577 & 1579 & & 1574 & & Ring Stretching ( $\left.\mathrm{P}_{Y}\right)^{e}$ \\
\hline & & & 1533 & 1532 & 1498 & 1487 & 1489 & 1486 & & & & $\begin{array}{l}\delta\left(\mathrm{NH}_{2}\right) \\
\nu_{\mathrm{s}}(\mathrm{C}=\mathrm{N})\end{array}$ & $\begin{array}{l}\mathrm{NH}_{2} \text { Detomation } \\
\mathrm{C}=\mathrm{N} \text { Stretching }(\operatorname{lm})^{e}\end{array}$ \\
\hline 1478 & 1485 & 1472 & 1448 & & 1458 & & & & 1483 & 1486 & 1450 & $v_{i}(\mathrm{C}=\mathrm{N})$ & $\mathrm{C}=\mathrm{N}$ Stretching $(\mathrm{Hy})$ \\
\hline & & & 1417 & & 1419 & & & & & & & $v_{3}\left(C_{+} C_{5}\right)$ & C.C Stretching \\
\hline & & & & & & & & & 1390 & & 1396 & $\delta\left(\mathrm{CH}_{3}\right)$ & $\mathrm{CH}_{3}$ Detormation \\
\hline 1380 & 1379 & 1389 & & & & & & & & & & $v_{s}\left(\mathrm{C}_{6} \mathrm{~N}_{1}\right)$ & $\mathrm{C}-\mathrm{N}$ Stretching $\left(\mathrm{H}_{Y}\right)$ \\
\hline & & & & & & 1348 & 1362 & 1353 & 1363 & 1377 & 1349 & $v_{i}(\mathrm{C}-\mathrm{N})$ & C-N Stretching (py) \\
\hline 1348 & 1340 & 1320 & & & & 1321 & 1320 & 1318 & & & & $v_{\mathrm{s}}(\mathrm{C}-\mathrm{N})$ & C-N Stretching $(\mathrm{lm})$ \\
\hline & & & 1290 & 1293 & 1293 & & & & & & & $v_{\mathrm{s}}\left(\mathrm{C}_{2}-\mathrm{N}_{3}\right)$ & C-N Stretching \\
\hline & & & & & & 1263 & & 1254 & & & & $v_{\mathrm{s}}\left(\mathrm{C}_{\mathrm{g}}-\mathrm{N}_{\mathrm{g}}\right)$ & C-N Stretching \\
\hline & & & 1240 & 1256 & 1226 & & & & 1224 & 1241 & 1233 & $v_{s}(\mathrm{C}-\mathrm{C})$ & Ring- $\mathrm{CH}_{3}$ Stretching \\
\hline & & & & & & & & & 1197 & 1205 & 1203 & & \\
\hline 1174 & & 1171 & & & & 1170 & 1178 & 1179 & & & & $v_{s}\left(\mathrm{C}_{5}-\mathrm{C}_{6}\right)$ & C.C Stretching \\
\hline & & & & & & 1078 & & 1085 & & & & & \\
\hline 1066 & & 1035 & 1024 & & 1033 & 1020 & & 1032 & 1016 & 1023 & 1019 & $v_{i}(\mathrm{~N}-\mathrm{C})$ & N-Sugar Stretching \\
\hline 908 & & 919 & 950 & & 949 & 950 & & 954 & & & & $\rho\left(\mathrm{NH}_{2}\right)$ & $\mathrm{NH}_{2}$ Rocking \\
\hline & & & 850 & & 847 & 850 & 851 & 850 & & & & $v_{\mathrm{s}}(\mathrm{N}-\mathrm{C}-\mathrm{N})$ & N-C-N Stretching \\
\hline 734 & 733 & 728 & 784 & 785 & 802 & & & & 792 & 789 & 796 & & Ring breathing (Py) \\
\hline & & & & & & 676 & 678 & 662 & & & & & Ring breathing (Im) \\
\hline & & & & & & & & & & & 243 & & All-O stretching \\
\hline & & & & & 231 & & & 225 & & & & & All-N stretching \\
\hline
\end{tabular}

"FT-Raman of powder. exicited with Nd:YAG $1064 \mathrm{~nm} 200 \mathrm{~mW}$. "Solution in water, excited with $\mathrm{Ar}^{+} 488 \mathrm{~mm} 200 \mathrm{~mW}$. 'On Au nancparticle. excited with Ti:Sapaere $710 \mathrm{~mm} 200 \mathrm{~mW}$. "Assigned from references [21, 22]. "Defined primidine (p.) and imidazole (im).

$1472 \mathrm{~cm}^{-1}$. It is concluded that the band at $728 \mathrm{~cm}^{-1}$ corresponds to the band at $734 \mathrm{~cm}^{-1}$ in the Raman spectrum of the solid and at $733 \mathrm{~cm}^{-1}$ in solution. which is attributed to the ring-breathing mode of adenine ${ }^{10: 2}$ This frequency agrees well with the spectrum of adenine reported by Koylin and co-workers at silver electrodes ${ }^{10.13 a}$ and in silver colloid. ${ }^{13 b}$ They assigned the strong band at $736 \mathrm{~cm}^{-1}$ as the primary skeletal vibrations of the adenine ring on a silver electrode. The relatively strong intensity of the $728 \mathrm{~cm}^{-1}$ band can be interpreted as a perpendicular standing (edge on) or tilted orientation of the adenine ring relative to the gold surface. This strong enhancement is due to a charge transfer between the aromatic adenine ring and the gold surface. ${ }^{15}$

It is worth noting that the ring-breathing frequency of $\mathrm{dA}$ is much different from $\mathrm{dC} . \mathrm{dG}$. and $\mathrm{dT}^{15}$ According to Raman analysis. the band at $734 \mathrm{~cm}^{-1}$ in the solid spectrum is not due to just the ring-breathing vibration. but another vibration that was assigned by an IR study of adenine-metal complexes to a coupled $\mathrm{NH}_{2}$ deformation and ring vibration. ${ }^{2+}$ This frequency was found to changes from 714 to $740 \mathrm{~cm}^{-1}$ depending upon the complex. In this work, the SERS spectrum of $\mathrm{N}$-deuterated dA was recorded to determine if the $\mathrm{NH}_{2}$ vibration is contributed to this assigned vibration. The $\mathrm{N}$-deuterated dA SERS spectrum (Figure 3D) exhibited a strong bands at $724 \mathrm{~cm}^{-1}$. which was slightly red-shifted from the nondeuterated spectrum (Figure 3C). This red-shift was smaller than that expected for a purely $\mathrm{N}-\mathrm{D}$ vibration. Based on this evidence. it is that the strong band at $728 \mathrm{~cm}^{-1}$ is due to a ring breathing vibration with a partial contribution from the amino group vibration.

With the exception of guanine derivatives. all purine derivatives give rise to normal Raman band of the ringbreathing vibration near $725 \mathrm{~cm}^{-1}$. In Figure 3, this corresponds to the bands at $734 \mathrm{~cm}^{-1}$ in the solid and at $733 \mathrm{~cm}^{-1}$ in solution. respectively. The frequency shift between nonnal and SERS spectra points out that the molecular and electronic structures of an adsorbed dA are slightly perturbed on the gold surface.

In Figure 1(a). the dA has four potential nitrogen binding

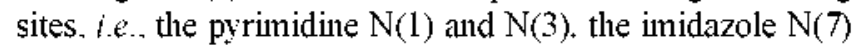
ring nitrogen, and the $\mathrm{N}(6)$ nitrogen of the exocyclic $\mathrm{NH}_{2}$ group. Since $N(9)$. which is the preferred binding site of adenine. is blocked by the deoxyribose substituent in $\mathrm{dA}$. $\mathrm{N}(7)$ becomes the primary binding site of the latter ligand when it is acting as temininal unidentate, with $N(1)$ and $N(7)$ being the most common binding sites of bridging bidentate dA.

Various proposals for the orientation of the adenine molecule with respect to the metal surface can be put forward. It can be postulated that the adenine ring has an orientation 


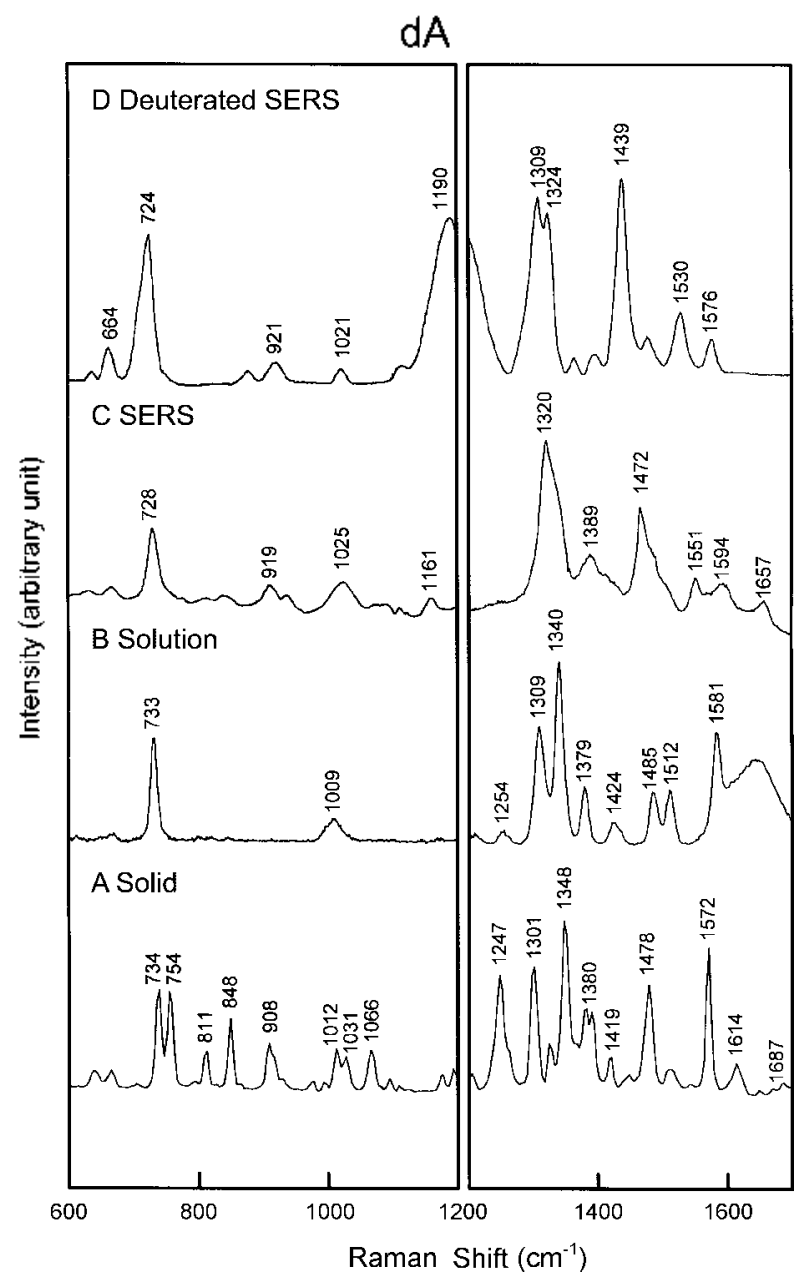

Figure 3. The Raman spectra of dA: (a) FT-Raman in solid, (b) Nonnal Raman in aqueous solution (saturated), (c) SERS on aqueous gold nanoparticles $\left(1.5 \times 10^{-5} \mathrm{M}\right)$, (d) SERS on gold nanoparticles in $\mathrm{D}_{2} \mathrm{O}$ for $\mathrm{N}$-Deuterated species $\left(1.5 \times 10^{-5} \mathrm{M}\right)$. The laser power and excitation wavelength is (a) $200 \mathrm{~mW}$ with $1064 \mathrm{~nm}$

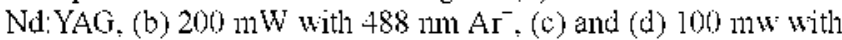
$7101 n n$ Ti: $\mathrm{Al}_{2} \mathrm{O}_{3}$ prism pumped $\mathrm{Ar}^{+}$laser.

parallel to the metal surface. ${ }^{102.25}$ It can also be concluded from the presence of a strong band at $1334 \mathrm{~cm}^{-1}$ in the SERS spectrum of adenine that adsorption takes place through the nitrogen atom on the 7-position of the ring. ${ }^{\text {laa }}$ This conclusion is based on the assumption that the most intense lines in the SERS spectrum are due to the atom in close proximity to the metal surface.

There exists a gold surface-adenine configuration which is relatively tight and corresponds to a very particular surfaceadenine complex. Any of the following possibilities would be a plausible candidate for the orientation of the adenine molecule in the gold surface-adenine complex: (1) a parallel arrangement. (2) a perpendicular arrangement through the $N(7)$ atom of the imidazole ring or the $N(1) . N(3)$ atoms of the pyrimidine ring. or (3) an arrangement through the external amino group.

Another dA SERS bands at 1472 and $1657 \mathrm{~cm}^{-1}$ were also observed (Figure 3C). Since the six-membered ring of adenine is aromatic. these bands may be related to high frequency ring modes of this aromatic heterocycle. which is generally coupled to the substituents. ${ }^{21.22}$ The band at 1657 $\mathrm{cm}^{-1}$ assigned to an $\mathrm{NH}_{2}$ scissoring vibration. and the strong band at $1472 \mathrm{~cm}^{-1}$ to the $\mathrm{C}=\mathrm{N}$ stretching vibration of the pyrimidine ring in the SERS spectnum. Supporting evidence for these assignments was obtained by comparing the SERS spectnum of the $\mathrm{N}$-deuterated $\mathrm{dA}$ molecule in $\mathrm{D}_{2} \mathrm{O}$ with the analogous undeuterated spectrum. The SERS band at 1657 $\mathrm{cm}^{-1}$ assigned to the $\mathrm{NH}_{2}$ scissoring vibration was redshifted to $1190 \mathrm{~cm}^{-1}$ in the deterated spectrum. and the band at $1472 \mathrm{~cm}^{-1}$ assigned to the $\mathrm{C}=\mathrm{N}$ stretching vibration shifted to $1439 \mathrm{~cm}^{-1}$ in deuterated form (Figure 3C-D).

Usually in deuterated $\mathrm{ND}_{2}$. it is red-shifted about $1 / \sqrt{2}$ times from $\sqrt{\mathrm{NH}_{2}} / \sqrt{\mathrm{ND}_{2}}$ and this agrees well with the present data. The vibrations originating in functional groups of the molecule near the metal surface are most strongly enhanced. Because several vibrations. in which the motion of the $\mathrm{C}(6)-\mathrm{NH}_{2}$ group participates. give rise to strong contributions in the SERS spectrum. it is concluded that the external amino group of adenine was connected to the metal surface. This agrees with the report that the $\mathrm{C}(6)-\mathrm{NH}_{2}$ group of the pyrimidine ring in $\mathrm{dA}$ can participate in the coordination to the Ag electrode surfaces. ${ }^{1 \text { th }}$ It is easy to place the external amino group in all DNA bases in such a position that it can bind to the surface. It is quite difficult for the N(7) group to make a contact with the surface without additional contacts of the external amino group on the $\mathrm{C}(6)$-position or of the backbone with the surface. It is. therefore unlikely that the $N(7)$ atom of adenine is directly connected to the gold surface. In the SERS spectra. the band at $1657 \mathrm{~cm}^{-1}$ is assigned to the $\mathrm{NH}_{2}$ scissoring vibration and is shifted by 42 $\mathrm{cm}^{-1}$ to the low frequency in $\mathrm{N}$-deuterated $\mathrm{dA}$ in $\mathrm{D}_{2} \mathrm{O}$. This indicates that the external amino group of $\mathrm{dA}$ participates in the surface binding process.

From the above discussion and metal complex studies. ${ }^{26}$ dA strongly interact with the gold surface through the $\mathrm{N}(7)$ nitrogen atom of an imidazole ring and the occurrence of strong contributions of the vibrations in which the external amino group participates in the SERS spectnum of adenine. indicating that the external amino group participated in the surface binding process. The proposed coordination structure to the gold nanoparticles is shown in 7(a).

2. dIC. Several atoms and bonds in $\mathrm{dC}$ such as $\mathrm{N}(3), \mathrm{C}=\mathrm{O}$ and $\mathrm{C}=\mathrm{N}$ can bind to the gold surface. It is known that the $\mathrm{N}(3)$ and the $\mathrm{C}=\mathrm{O}$ group in cytosine have deep potential minima for the interaction with an external point charge. ${ }^{27}$ With cytidine, it has been reported that hard metal ions bind to the $\mathrm{C}=\mathrm{O}$ group whereas soft metals such as silver bind to $\mathrm{N}(3)$. in general. From X-ray crystallographic studies ${ }^{28} 1$ metlylcytosine. was found to bind to Pt via N(3) and to $\mathrm{Ag}$ through $N(3)$ and $C=O$. Since the gold nanoparticles are expected to be softer than silver ion. it is expected that the interaction of $\mathrm{N}(3)$ with the surface would be more important than that of $\mathrm{C}=\mathrm{O}$.

In the SERS spectrum of $\mathrm{dC}$, the highest frequency band at $1638 \mathrm{~cm}^{-1}$ is assigned to the $\mathrm{C}=\mathrm{O}$ stretching vibration of the carbonyl group. This band does not shift in $\mathrm{D}_{2} \mathrm{O}$ (Figure 


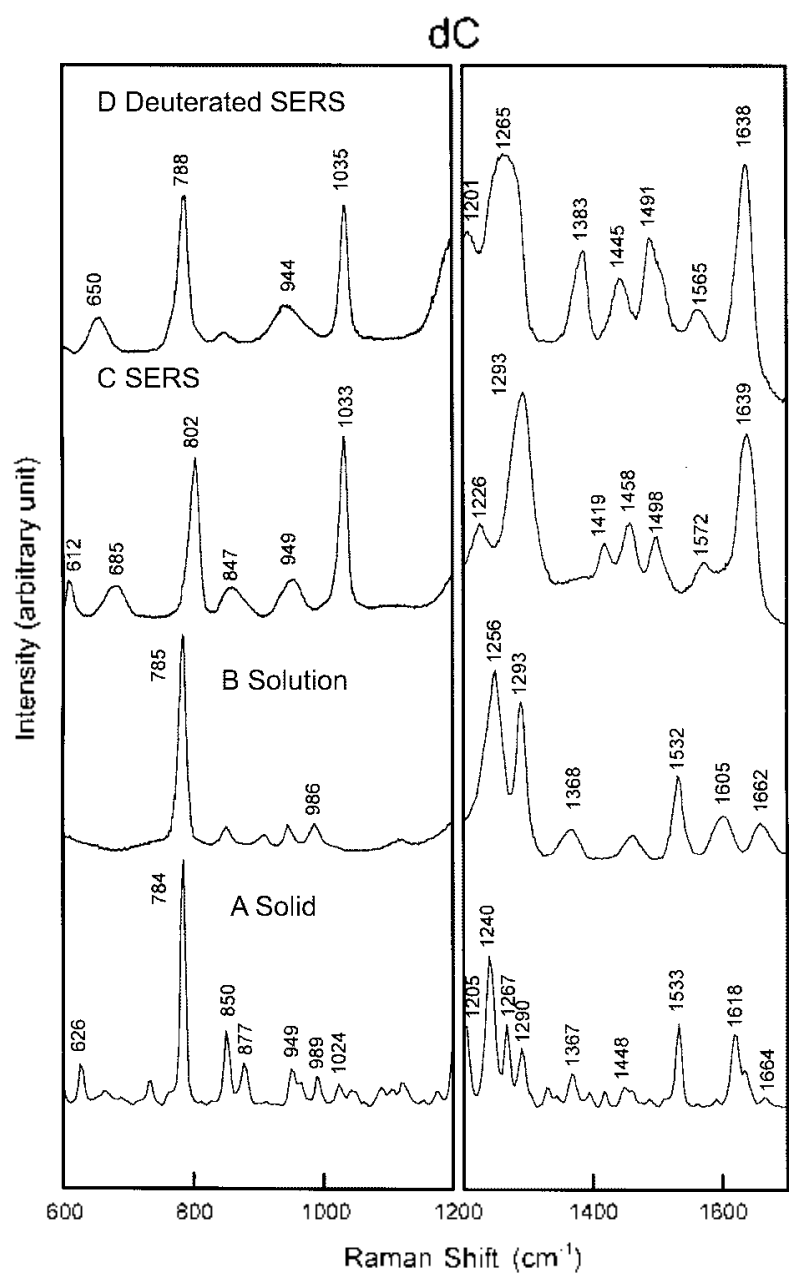

Figure 4. The Raman spectra as in Figure 3 of dC. The spectra of (a) and (b) have been substracted by baseline.

4D), which excludes the possibility of the band arising from a coordinated amino group. ${ }^{29}$ In the FT-Raman spectrum of solid $\mathrm{dC}$. the $\mathrm{C}=\mathrm{O}$ stretching vibration appears at $1664 \mathrm{~cm}^{-1}$ while the vibration in the aqueous spectrum is observed at $1662 \mathrm{~cm}^{-1}$. The coordinated species exhibits a large shift $(22$ $\mathrm{cm}^{-1}$ ) to lower frequencies when compared to the solution spectrum. This indicates that the electron donation of the carbonyl group to the surface would decrease the bond order. resulting in a decrease in the vibrational frequency.

In the FT and normal spectra. the weak $\mathrm{C}=\mathrm{O}$ stretching vibration appears at $1664 \mathrm{~cm}^{-1}$ and $1662 \mathrm{~cm}^{-1}$. respectively. This band shows a sharp and intense peak in the SERS spectrum on gold nanoparticles and is shifted to the 1639 $\mathrm{cm}^{-1}$. The shift of this band to the lower frequency is ascribed to a decrease in the double bond character of the $\mathrm{C}=\mathrm{O}$ as a consequence of the electron delocalization induced by coordination of the $\mathrm{C}=\mathrm{O}$ group on the gold metal surface. Thus this shift can be explained. on the basis of the chemical SERS theory. by a charge transfer taking place from the pyrimidine ring of $\mathrm{dC}$ to gold surface.

Further evidence for binding of the nitrogen atom is provided by a strong SERS band at $1293 \mathrm{~cm}^{-1}$. which constitutes one of the most intense in the SERS spectrum.
This band exhibits some shifts both in aqueous solution and in the solid. This intense band is assigned to the $\mathrm{C}(2)-\mathrm{N}(3)$ stretching and suggests a strong interaction between this nitrogen atom and the gold surface. This band appreciably downshifts by $25 \mathrm{~cm}^{-1}$ to $1265 \mathrm{~cm}^{-1}$ when the amino group at $C(4)$ of $d C$ is changed to the $N$-deuterated $N_{2}$ in $D_{2} O$. The strong SERS band at $1033 \mathrm{~cm}^{-1}$ is assigned to the C$\mathrm{N}(1)$ stretching vibration of a sugar-pyrimidine ring. Comparing with others. this band in $\mathrm{dC}$ is very strong and probably due to coordination to the gold of the carbonyl group at $\mathrm{C}(2)$. This possibility is deduced that the corresponding bands are very strong on the gold surface. whereas they are very weak in the solid as well as in solution. Both the intensity and position are unaffected by changing the amino group at $\mathrm{C}(4)$ to the $\mathrm{ND}_{2}$ in $\mathrm{D}_{2} \mathrm{O}$. which provides supporting evidence for this assignment.

The enhancement of $\mathrm{C}=\mathrm{O}$ stretching band reveals the proximity of the carbonyl group to the gold surface. Moreover. the existence of the band assigned to the $\mathrm{NH}_{2}$ group deformation at $1498 \mathrm{~cm}^{-1}$. appearing at $1532 \mathrm{~cm}^{-1}$ in aqueous solution. shows that the amino group is very close to the gold surface. The intense band at $1293 \mathrm{~cm}^{-1}$ assigned to the $\mathrm{C}(2)-\mathrm{N}(3)$ stretching vibration in the SERS spectrum might indicate either the closeness of the ring nitrogen atom to the metal surface. in accordance with the suggested proximity of the $\mathrm{C}=\mathrm{O}$ group. or a non-parallel orientation of the adsorbate on the metal surface. The ring breathing band at $802 \mathrm{~cm}^{-1}$ shows a typical frequency when atoms of a sixmembered ring bind to the metal surface.

The FT-Raman of the solid. normal Raman in solution. and SERS spectra of $\mathrm{dC}$ on gold nanoparticles and of deuterated $\mathrm{dC}$. respectively. are compared in Figure 4. It is found that considerable frequency shifts occur throughout the spectnum when $\mathrm{dC}$ is adsorbed to gold nanoparticles. The strong band at $802 \mathrm{~cm}^{-1}$ in the SERS spectra is attributed to the ring breathing vibration of the pyrimidine skeleton. 21.22 The corresponding band of ring breathing vibration of $\mathrm{dC}$ is observed at $784 \mathrm{~cm}^{-1} .785 \mathrm{~cm}^{-1}$ in the solid and in solution. respectively: The red-shift of this band with respect to its analogue in the FT and normal Raman spectra is a characteristic of numerous aromatic systems adsorbed to metal surfaces. ${ }^{\text {ll }}$ This red-shift can be attributed to the redistribution of an electronic charge density taking place in the ring as a consequence of adsorption. This can be explained by the facts that some parts of a cytosine ring can directly interact with the gold surface on adsorption. The appearance of a band at $231 \mathrm{~cm}^{-1}$ assignable to Au-cytosine vibration suggests that there is a metal-adsorbate interaction. possibly $\mathrm{Au}-\mathrm{N}$ stretching vibration.

Another notable SERS band of $\mathrm{dC}$ recorded on gold nanoparticles shows an unique $\mathrm{Au}-\mathrm{N}$ vibration band at 231 $\mathrm{cm}^{-1}$. suggesting a closer position of the nitrogen atom involved in the interaction when the gold is used as a substrate. The presence of only one band suggests the existence of an unique coordination site. From the above results and references. ${ }^{30.31}$ it is proposed that the $\mathrm{dC}$ binds to the gold surface via the $N(3)$ nitrogen atom of the pyrimidine 


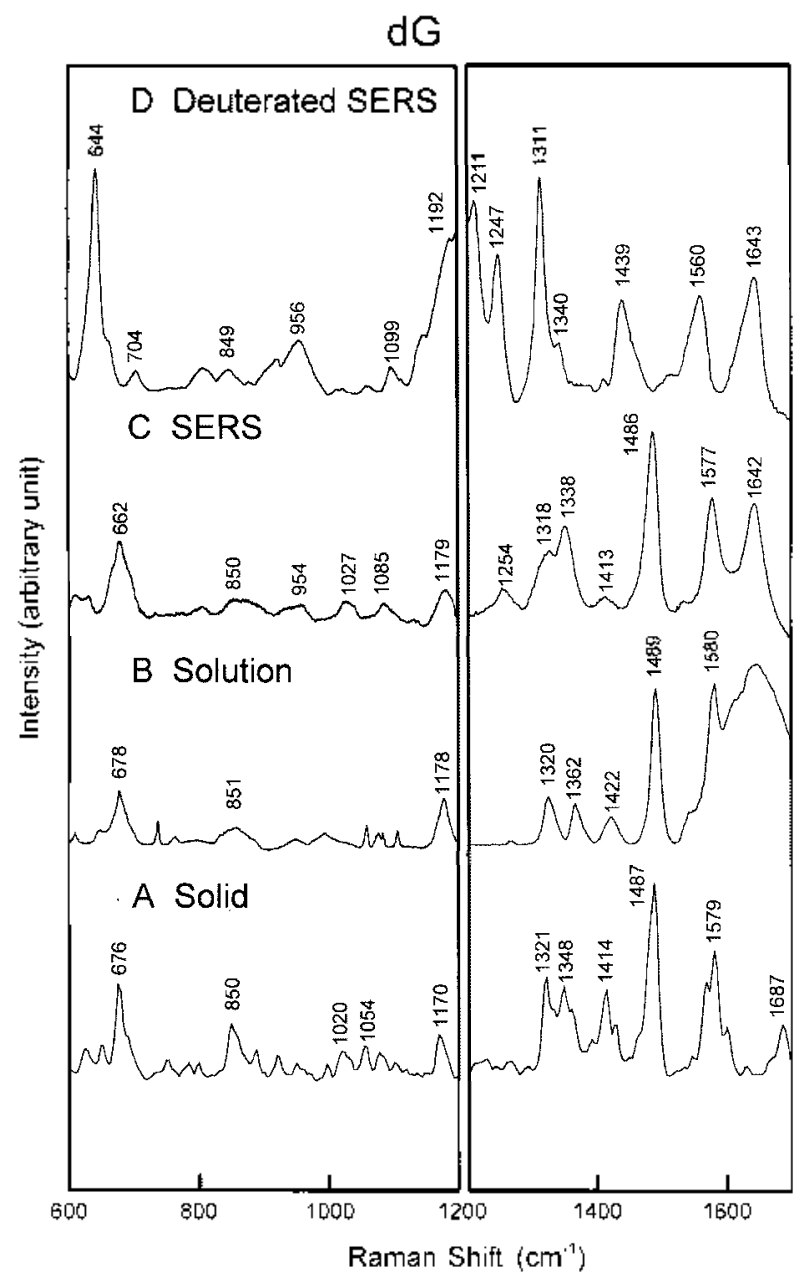

Figure 5. The Raman spectra as in Figure 3 of dG. The spectra of (a) and (b) have been subtracted by baseline.

ring with some contribution from the carbonyl group at $\mathrm{C}(2)$. The suggested coordination structure of $\mathrm{dC}$ on gold nanoparticles is shown in Figure 7(b).

3. dG. The uncharged guanine derivatives are very insoluble in neutral water and it has not been mostly studied without the $\mathrm{pH}$ adjustment. ${ }^{12.17 .18}$ However. in this work. I can take a good SERS spectnum of $\mathrm{dG}$ at the neutral solution in spite of the very low solubility as plotted in Figure 5 and summarized in Table 1.

In Figure 5C. I can see the strong SERS band of the carbonyl band stretching vibration at $1642 \mathrm{~cm}^{-1}$ and this strong stretching vibration of the $\mathrm{C}=\mathrm{O}$ group gives rise to a sharp band at $1642 \mathrm{~cm}^{-1}$ which is absent in the SERS spectra on silver. ${ }^{17}$ This intense band is appreciably shifted to lower wavenumbers with respect to the same band at $1687 \mathrm{~cm}^{-1}$ in the solid spectnum recorded by FT-Raman. which indicates that the $\mathrm{C}=\mathrm{O}$ group strongly interacts with the gold nanoparticles surface. This agrees well with the corresponding SERS spectra obtained by Camafeita et all. ${ }^{1 \S}$ More specially. the shift to lower wavenumbers indicates that the molecule adsorbs on the gold surface mainly in its enolic form as a consequence of an increase in the ring electronic delocalization.
I can also see the strong SERS band of the carbonyl band stretching vibration at $1642 \mathrm{~cm}^{-1}$ in Figure $5 \mathrm{C}$. This band is shifted by $45 \mathrm{~cm}^{-1}$ to higher wavenumber in comparison to the solid FT-Raman spectrum., suggesting that the oxygen atom at $\mathrm{C}(6)$ is bound to the gold nanoparticles surface in the enolic form rather than the keto form. This large shift results from restructuring the ring charge. clearly indicating a strongly direct interaction between $\mathrm{dG}$ and the gold surface through the $\mathrm{C}=\mathrm{O}$ group. Accordingly, the carbonyl group plays an important role when the $\mathrm{dG}$ interacts with the gold surface through the pyrimidine ring.

With a strongly direct interaction between the molecule and surface through the $\mathrm{C}=\mathrm{O}$ group. $\mathrm{N}(1)$ atom of the ring would also give rise to a shift to higher wavenumbers of these vibrations related to the ring. I can see these intense SERS bands at 1338. 1486. and $1577 \mathrm{~cm}^{-1}$ in Figure $5 \mathrm{C}$. which assigned to. in turn. the $\mathrm{C}-\mathrm{N}$ stretching. $\mathrm{C}=\mathrm{N}$ stretching. and ring stretching. respectively. at the pyrimidine ring. Especially the relatively strong ring band at $1486 \mathrm{~cm}^{-1}$ suggests that the pyrimidine ring of $\mathrm{dG}$ adopts preferably a perpendicular position on the gold surface through the nitrogen atom.

The bands at 1318 and $1254 \mathrm{~cm}^{-1}$ assigned to the pyrimidine ring vibration frequencies ${ }^{23}$ exhibit changes in intensity and frequency upon binding to the gold nanoparticles surface. The change of this band in the spectra of all metal nucleoside complexes are most likely due to $\mathrm{N}(1)$-metal interaction. Regarding bridging bidentate guanine. N(1). $N(3)$ and $N(7)$ would be equally likely to act as biding sites on metal. However. dG has the deoxyribose substituent at $N(9)$, which could conceivably introduce sufficient steric hindrance as to prevent coordination of this ligand through $\mathrm{N}(3)$. From the structure of $\mathrm{dG}$. it may be postulated that $\mathrm{N}(1) . \mathrm{NH}_{2}$ at $\mathrm{C}(2), \mathrm{N}(7), \mathrm{C}=\mathrm{O}$ at $\mathrm{C}(6)$, and some of their combination may be involved as a binding site when binding to the gold surface. In Figure 5C. I cannot find any bands that the amino group interacts with the gold surface and that was much red-shifted for $\mathrm{N}$-deuterated $\mathrm{dG}$ in Figure 5D. This can confirm that the amino group at $\mathrm{C}(2)$ is not the site of binding on gold surfaces.

From other similar SERS study. ${ }^{31}$ 2-Deoxyinosine (dI), which is structurally similar to $\mathrm{dG}$. but without an amino group. behaves dislikes $\mathrm{dG}$ in interaction with an gold metal surface. The SERS spectrum of $\mathrm{dI}$ on gold surface is very similar to that of $\mathrm{dA}$. It means that the amino group at $\mathrm{C}(2)$ position play an important role to the bind structure of $\mathrm{dG}$ on gold surface. In $\mathrm{dG}$. the hydrogen at $\mathrm{N}(1)$ migrate to the amino group after deprotonation in the neutral solution. Accordingly. N(1) can be a character of anion and can play a role to the binding site. In $\mathrm{dI}$. however. the hydrogen at N(1) cannot migrate because it is without the amino group. Because the hydrogen at $\mathrm{N}(1)$ exist. the binding site of $\mathrm{dI}$ have to prefer to $\mathrm{N}(7)$ nitrogen to gold surface. Therefore. both bind to the gold surface with the same site $N(7)$ and I can observe the very similar spectra between $\mathrm{dA}$ and $\mathrm{dI}$. It has been reported that guanine functions as a chelating agent. binds through $\mathrm{N}(1)$ to metal ion. ${ }^{32}$ The possibility of 
coordination of guanine derivatives through $\mathrm{C}=\mathrm{O}$ group. in metal complex with bridging or chelating guanines has been proposed in some cases. ${ }^{33}$ The coordinative position of $\mathrm{N}(1)$ and $\mathrm{C}=\mathrm{O}$ group has also been proposed as active sites of bonding in aqueous solutions with metals depending on $\mathrm{pH}^{3+}$

All purines derivatives except guanine give rise to a strong Raman band about ring-breathing mode near $725 \mathrm{~cm}^{-1}$. The intense SERS band of $\mathrm{dG}$ appears at $662 \mathrm{~cm}^{-1}$ in Figure $5 \mathrm{C}$ and corresponds to the ring breathing mode. This band appreciably shifted by $18 \mathrm{~cm}^{-1}$ to higher wavenumbers with the same band in the normal Raman spectrum recorded in saturated aqueous solution, which appears at $678 \mathrm{~cm}^{-1}$. This band also appears at $676 \mathrm{~cm}^{-1}$ in the solid when recorded by FT-Raman spectnum. For $\mathrm{N}$-deuterated dG. this frequency is slightly shifted to the lower range. It means that the ring of $\mathrm{dG}$ has a strongly direct interaction between the molecule and the surface through the nitrogen of the pyrimidine ring.

The presence of a broad. intense band at $225 \mathrm{~cm}^{-1}$ indicates the existence of a metal-adsorbate interaction and assigned to the Au-N(1) stretching vibration. This means that the $\mathrm{dG}$ molecule interacts through the nitrogen atom of the pyrimidine ring. The SERS band at $225 \mathrm{~cm}^{-1}$ is postulated to be due to the metal-nitrogen stretching vibration and reveals the existence of $\mathrm{Au}-\mathrm{N}$ interaction. Accordingly: this suggests the $\mathrm{dG}$ molecule interacts with the gold surface through the $\mathrm{N}(1)$ atom of the pyrimidine ring. In this molecule. the N(l) atom seems to play an important role as the side of the molecule with a tendency to interact with the gold in the colloid.

In view of the above result. an interaction of $\mathrm{dG}$ with the gold which implicates both the carbonyl group and the N(1) atom of the pyrimidine ring is proposed. The coordination structure to the gold surface is suggested in Figure 7(c).

4. dT. The intense SERS band of dT appeares at $1647 \mathrm{~cm}^{-1}$ which is attributed to the carbonyl stretching vibration. The corresponding bands of FT- and normal Raman are showing at 1664 and $1665 \mathrm{~cm}^{-1}$ in the solid and solution state. respectively: As shown in Figure 1. dT has two different carbonyl groups. $\mathrm{C}(2)=\mathrm{O}$ and $\mathrm{C}(4)=\mathrm{O}$. According to the study of thymine. ${ }^{1+}$ the two normal Raman bands at 1691 and $1657 \mathrm{~cm}^{-1}$ were attributed to the $C(2)=O$ and $C(4)=O$ stretching modes. respectively but only one band at 1652 $\mathrm{cm}^{-1}$ could be seen in the SERS spectnum. The different position of the carbonyl stretching modes in the normal Raman spectrum seemed to occur because the $\pi$-electrons of the $\mathrm{C}(2)$ carbonyl band were isolated from the ring $\pi$ electrons so no electron delocalization took place. in contrast with the situation for the $\mathrm{C}(4)$ carbonyl group. The occurrence of a single band in the SERS spectrum is either because both carbonyl stretching modes vibrate with equal frequencies or because only one vibration mode can be seen. In our spectra of dT in Figure 6A-D. I can observe only one carbonyl band in case of all spectra. respectively. Therefore. it can be concluded that the $1647 \mathrm{~cm}^{-1}$ in the SERS spectrum results from one mode rather than that both modes occur at the same position. In the case that the 1647

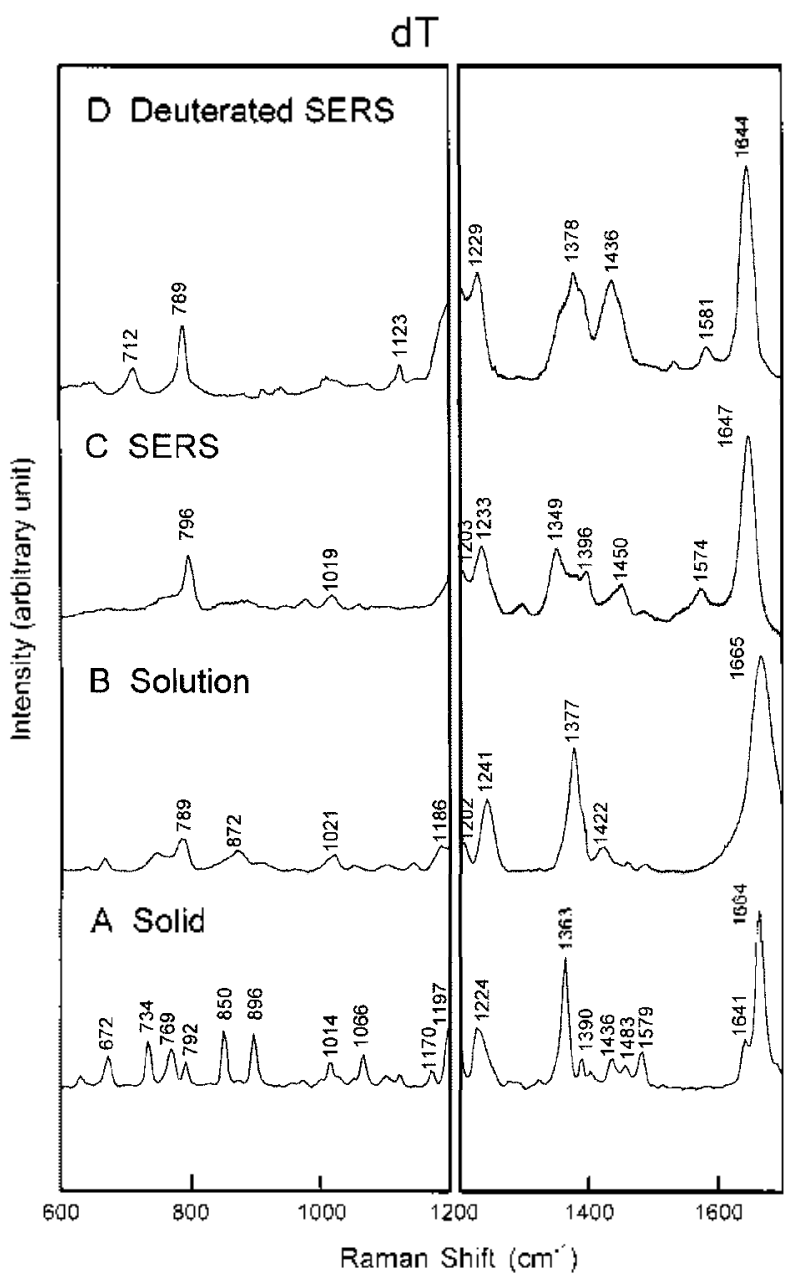

Figure 6. The Raman spectra as in Figure 3 of dT. The spectrum of (b) has been subtracted by baseline.

$\mathrm{cm}^{-1}$ band arises from one mode only. it would most likely correspond to the $\mathrm{C}(4)=\mathrm{O}$ stretching vibration mode. This possibility suggests that the orientation of the molecular plane is perpendicular to the surface instead of being parallel to it. ${ }^{10.14}$ If the $1647 \mathrm{~cm}^{-1}$ in the SERS spectnum is due to the $C(4)=O$ stretching vibration without the $C(2)=O$ coordination, this carbonyl group is strongly bound to the gold metal surface. As a consequence of an increase on the ring electronic delocalization. the SERS band of the carbonyl group is shifted by $18 \mathrm{~cm}^{-1}$ to higher wavenumbers (Figure 6C).

At $\mathrm{pH}$ 7. a possible interaction site of dT with the gold surface takes place only on the carbonyl group at $C(2)$ and C(4). As shown in Figure 6C. the strong SERS band at 1647 $\mathrm{cm}^{-1}$ is assigned the $\mathrm{C}(4)=\mathrm{O}$ stretching vibration. The corresponding Raman shifts are, respectively, 1664 and $1665 \mathrm{~cm}^{-1}$ in the solid and solution state. The $18 \mathrm{~cm}^{-1}$ red-shift for $\mathrm{C}=\mathrm{O}$ in the SERS spectrum is due to a strong interaction between the $\mathrm{C}=\mathrm{O}$ group and the gold surface. resulting from a charge transfer from the carbonyl group to the gold. Direct coordination of the gold to the $\mathrm{C}=\mathrm{O}$ group of the pyrimidine ring is inferred from the chares observed on the SERS spectrum of the corresponding bands at $\mathrm{C}=\mathrm{O}$ stretching vibration. 
In the SERS spectrum strong bands appear at 1233 and $1349 \mathrm{~cm}^{-1}$. which is also some strongly present at 1241 . $1377 \mathrm{~cm}^{-1}$ in solution Raman spectra (Figure 6B). and which can be assigned to the ring- $\mathrm{CH}_{3}$ stretching and $\mathrm{C}(4)-\mathrm{N}(3)$ stretching vibration of the pyrimidine ring. The $\mathrm{C}(4)-\mathrm{N}(3)$ stretching vibration is shifted by $28 \mathrm{~cm}^{-1}$ lower due to interaction to the gold surface through the $\mathrm{C}(4)=\mathrm{O}$ group. These can be ensured by observations that the band at $1233 \mathrm{~cm}^{-1}$ is almost unchanged. whereas $1349 \mathrm{~cm}^{-1}$ is shifted in the SERS spectrum of $\mathrm{N}$-deuterated $\mathrm{dT}$ after the hydrogen attached to the $\mathrm{N}(3)$ atom in $\mathrm{dT}$ easily undergo deuterium exchange in $\mathrm{D}_{2} \mathrm{O}$ (Figure 6D).

Another important band of $\mathrm{dT}$ in the SERS spectnum is for the ring-breathing vibration mode of the pyrimidine ring. Normal Raman spectra of all pyrimidines are found to contain an intense band near $780 \mathrm{~cm}^{-1}$. The corresponding band of dT in the SERS spectrum is showing at $796 \mathrm{~cm}^{-1}$ and FTand normal Raman spectra in the solid and solution state are corresponding at 792 and $789 \mathrm{~cm}^{-1}$. respectively. Comparison of the above frequencies does not show a specific frequency red-shift of the ring-breathing vibration in the spectral range around $790 \mathrm{~cm}^{-1}$. This indicates that although $\mathrm{dT}$ some interacts to the gold surface through the $\mathrm{C}(4)=\mathrm{O}$ group a directly strong coordination does not exist in this case.

The most characteristic band of the internal mode belongs to the in-plane ring-breathing modes and appears at $796 \mathrm{~cm}^{-1}$ in the SERS spectrum. No significant frequency shifts are observed when the measured FT- and normal Raman scattering frequencies in the solid and solution state are compared. Normal Raman spectra of all pyrrimidines are found to contain an intense band near $780 \mathrm{~cm}^{-1}$. It has been previously demonstrated that these bands shift to the lower range when

Table 2. Sunnnary of comparison with nomal Raman and SERS frequencies $\left(\mathrm{cm}^{-1}\right.$ ) for Ring-breathing and Exocylic modes of the DNA Nucleoside

\begin{tabular}{|c|c|c|c|c|c|}
\hline & & Ring-breathing & $C(2)=0$ & $C(4)=0$ & $\partial \mathrm{NH}_{2}$ \\
\hline \multirow[t]{4}{*}{$\mathrm{dA}$} & solid & 734 & & & 1687 \\
\hline & solution in $\mathrm{H}_{2} \mathrm{O}$ & $73 \hat{3}$ & & & \\
\hline & on $\mathrm{Au}$ sol in $\mathrm{H}_{\hat{\Sigma}} \mathrm{O}$ & 728 & & & 1657 \\
\hline & on $A u$ sol in $D_{2} O$ & 724 & & & 1190 \\
\hline \multirow[t]{4}{*}{$\mathrm{dC}$} & solid & 784 & 1664 & & \\
\hline & solution in $\mathrm{H}_{2} \mathrm{O}$ & 785 & 1662 & & \\
\hline & on $\mathrm{Au}$ sol in $\mathrm{H}_{2} \mathrm{O}$ & 802 & 1639 & & \\
\hline & on $A u$ sol in $D_{s} O$ & 788 & 1638 & & \\
\hline \multirow[t]{4}{*}{ dG } & solid & 676 & 1687 & & \\
\hline & solution in $\mathrm{H}_{2} \mathrm{O}$ & 678 & & & \\
\hline & on $\mathrm{Au}$ sol in $\mathrm{H}_{\star} \mathrm{O}$ & 662 & 1642 & & \\
\hline & on $\mathrm{Au}$ sol in $\mathrm{D}_{2} \mathrm{O}$ & 644 & 1643 & & \\
\hline \multirow[t]{4}{*}{ dT } & solid & 792 & & 1664 & \\
\hline & solution in $\mathrm{H}_{2} \mathrm{O}$ & 789 & & 1665 & \\
\hline & on $\mathrm{Au}$ sol in $\mathrm{H}_{\star} \mathrm{O}$ & 796 & & 1647 & \\
\hline & on $A u$ sol in $D_{2} O$ & 789 & & 1645 & \\
\hline
\end{tabular}

(a)

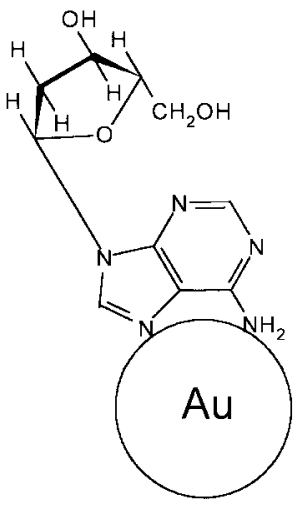

(c)

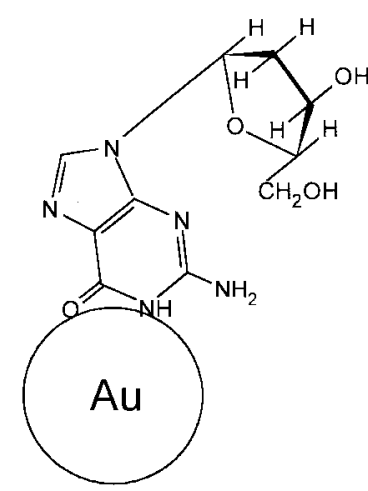

(b)

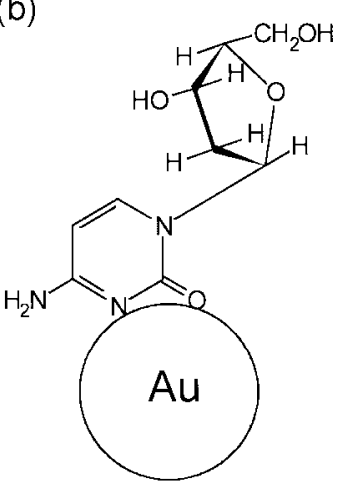

(d)

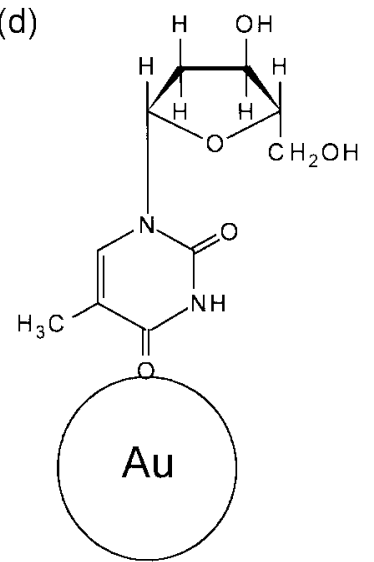

Figure 7. Proposed structures of DNA nucleosides bound to the gold nanoparticles: (a) dA, (b) dC, (c) dG, and (d) dT.

the parts of a ring participate in coordination to the metal surface. For dT, the ring-breathing vibration between on the gold and in the solid or solution state are almost unchangeable as sumnarized in Table 2. indicating a weak or no interaction between the ring and the gold nanoparticles surface.

In addition. other bands due to the ring vibration $\left(\delta_{\mathrm{H}}\right.$ and $\delta(\mathrm{N})$ do not vary significantly in Figure 6B-D. However, one band appearing at $1450 \mathrm{~cm}^{-1}$. which is assigned to the $\mathrm{C}=\mathrm{N}$ stretching vibration. exhibits a significant red-shift in $\mathrm{dT}$. suggesting the existence of strong interaction

A sharp band at $243 \mathrm{~cm}^{-1}$ indicates the existence of a metal-adsorbate interaction and is assignable to the goldoxygen stretching vibration. This points to a direct proof that the carbonyl group of $\mathrm{dT}$ interacts with the gold surface. Analogousiy: another band is observed at $242 \mathrm{~cm}^{-1}$. assignable to $\mathrm{Au}-\mathrm{O}$ stretching vibration. which means some interaction between $\mathrm{dT}$ and the gold surface.

From the results and references. ${ }^{35}$ it is postulated that the oxygen at $\mathrm{C}(4)$ is the main interaction between $\mathrm{dT}$ and the gold surface. The proposed structure of $\mathrm{dT}$ bound to the gold surface is shown in Figure 7(d).

\section{Conclusions}

Good-quality SERS spectra of the DNA nucleosides on gold nanoparticles can be obtained with 710 num excitation. using $\mathrm{Ti}_{2} \mathrm{Al}_{2} \mathrm{O}_{3}$ prism pumped $\mathrm{Ar}^{+}$laser. They show vibrational modes of the purine and pyrrimidine bases. with dramatic 
vibrations in the coordination pattern. These vibrations are helpful in making vibrational assignments and determining the coordination structures. Because the $\mathrm{C}(1)$ carbon atom of deoxyrribose is bonded to $\mathrm{N}(1)$ of a pyrimidine or $\mathrm{N}(9)$ of a purine. the coordination site of DNA nucleosides on gold surface is much different from that of bases.

According to UV-Visible absorption of gold nanoparticles after modifying with DNA nucleosides. the absorption increment rates of gold nanoparticles bound by $\mathrm{dA}, \mathrm{dC}$. and $\mathrm{dG}$ are much faster than that of $\mathrm{dT}$. This suggests that the coordination of the $\mathrm{dA} . \mathrm{dC}$ and $\mathrm{dG}$ is more affinitive than that of dT. As the result of SERS spectra. a dA mainly binds to gold nanoparticles vi $\mathrm{N}(7)$ nitrogen atom of the imidazole ring. which the $\mathrm{C}(6)-\mathrm{NH}_{2}$ group also participates in the coordination process.

In case of $\mathrm{dC}$. it binds to the gold surface via the N(3) nitrogen atom of the pyrimidine ring with a partial contribution from the oxygen of $\mathrm{C}(2)=\mathrm{O}$ group. A coordination of $\mathrm{dG}$ to the gold implicates both the $\mathrm{N}(1)$ atom and the oxy'gen of $\mathrm{C}(6)=\mathrm{O}$ group of the pyrimidine ring. It seems that although the DNA nucleosides have the two different nitrogen of a pyrimidine ring and amino group. the $N(1)$ nitrogen atom of a pyrrimidine ring has a higher affinity after the hydrogen migrates to the amino group.

Conversely. only dT binds to the gold surfaces via the oxy'gen of $\mathrm{C}(4)=\mathrm{O}$ group of the py rimidine ring. Accordingly. the nitrogen atom of an imidazole or pyrimidine ring in DNA nucleosides can be bound strongly to a gold surface than the oxy'gen atom of a carbonyl group. It is obvious that these results can also play an important role to illuminate the binding structure to metal surface in the Watson-Crick type base pairing of the double helix in DNA.

Acknow ledgment. Author thanks for Prof. Mirkin \& Dr. Storhoff at Northwestern University.

\section{References}

1. (a) Xu. X. H.: Bard. A. J. J. Am. Chem. Soc, 1995, 117, 26272631. (b) Mucic. R. C.: Herrlein. M. K.: Mirkin. C. A.: Letsinger. R. L. Chem. Conmun 1996, 555-557. (c) Ihara, T.: Nakavama, M.: Murata, M: Nakano. K.: Maeda, M. Chem. Commm. 1997. $1609-1619$

2. (a) Wang. J.: Paleèek. E.: Nielsen. P. E.: Rivas. G.: Cai. X: Shiraishi. H.: Dontha. N.: Luo. D.: Farias. P. A. M. J. Am. Chem. Soc. 1996, 118, 7667-7670. (b) Thiel. A. J.: Frutos A. G.: Tordant. C. E.: Corn. R. M: Smih. L. M. Aanal. Chen. 1997. 69. 49484956 .

3. Mirkin. C. A.: Letsinger. R. L.: Mucic. R. L.: Storhotf. J. J. Nature 1996. 382. 607-609.

4. Elghanian. R: Storhoff. J. J.: Mucic, R. L.: Letsinger. R. L.: Mirkin C. A. Science 1997. 277, 1078-1081.

5. Storhoft, I. J; Elghanian. R: Mucic, R. L: Mirkin. C. A.: Letsinger. R. L. J. Am. Chem. Soc. 1998. I20. 1959-1964.

6. (a) Mahtab. R.: Rogers. J. P: Murphy. C. J. J. Am. Chem. Soc. 1995. 117. 9099-9100. (b) Alivisatos. A. P.: Johnsson. K. P.: Peng. X.: Wilson. T. E.: Loweth. C. J.: Bruchez. Jr. M. P.: Schultz. P. G. Nature 1996, 382, 609-611.

7. Hegner. M.: Wagner, P.: Semenza, G. FEBS Lett. 1993, 336. 452456

8. Zimmermann. R. M.: Cos. E. C. Nucleic Acids Res. 1994. 22.
492-497

9. Surface Enhanced Rantan Scattering. Chang, R. K.: Furtak, T. E., Eds.: Plenum Press: New York. 1982.

10. (a) Koglin. E.: Séquaris. J. M.: Valenta. P. J. Mol. Struct. 1980. 60. 421-425. (b) Ervin. K. M.: Koglin. E.: Séquaris. J. M.: Valenta. P.: Nünberg. H. W. J. Electromal Chem. 1980. 114. 179-194.

11. (a) Watanabe, T, Kawanami. O,- Katoh, H.: Honda, K. Surf. Sci 1985. 158. 341-351. (b) Koglin, E.: Lewinsky, H.: Sequaris, J. M. Surf. Sci. 1985. 158.370-380

12. (a) Koglin1. E.: Séquaris. T. M.: Valenta. P. In Suface Studies with Lasers: Aussenegg. F. R.: Leitner. A.: Lippitsch. M. E.. Eds.: Springer-Verlag: Berlin. 1983: pp 64-71. (b) Sequaris, J. M.; Fritz, $\mathrm{J} ;$ Lewinshy, H:; Koglin. E. J. Coll Interf. Sci. 1985. 105. 417 425 .

13. (a) Koglin. E.: Séquaris. J. M.: Valenta. P. J. Hol. Struct. 1982. 79. 185-189. (b) Koglin. E.: Séquaris. T. M.: Fritz. J. C.: Valenta. P. J. 1fol. Struct. 1984. 114.219-223.

14. (a) Otto. C.: van den Tweel. T. J. J.: de Mul. F. F. M.: Greve. J. J. Ruman Spectrose. 1986. 17, 289-298. (b) Otto. C.: de Mul. F. F. M.; Huizinga, A.; Greve. J J. Ph.s. Chem. 1988, 92. 1239-1244.

15. Suh. J. S.: Moskovits. M. I. Am. Chem. Soc 1986. 108. 471l4718 .

16. Koglin. E.: Séquaris. T. M. In Topics in Cument Chemistry: Springer-Verlag: Berlin, 1986; Vol. 134 , pp 1-57.

17. Oh, W. S.: Kim. M. S.; Suh, S. W. J. Raman Spectrosc. 1987, 18 . $253-258$.

18. (a) Sánchez-Cortés. S.: García-Ramos. J. V. rib. Spectrosc. 1993. 4. 185-192. (b) Camafeita. L. E.: Sánchez-Cortés. S.: GarcíaRamos. J. V. J. Raman Spectrosc. 1995. 26. 149-154

19. See reviews, for instance: (a) Frens, G. Nature Phys. Sci. 1973. 241. 20-22. (b) Creighton. J. A.: Blatchford. C. G.; Albrecht. M. G. J. Chem. Soc. Foradan Trans. 11 1979. 75.790-798.

20. (a) Caldwell. W. B.: Campbell. D. J.: Chent. K: Herr. B. R.: Mirkin. C. A.: Malik. A.: Durbin. M. K.: Dutta. P.: Huang. K. G. $J$. Am. Chem. Soc. 1995. 117.6071-6082. (b) Campbell. D. T.: Herr. B. R: Hulteen. J. C: Van Duyne, R. P; Mirkin. C. A. J. Ain. Chent Soc 1995, 118. 10211-10219.

21. (a) Mathlouthi. M.: Seuvre, A.M:- Koenig. J. Carbolndt Res. 1984. 131. 1-15. (b) ibid. 1986. 146. 1-13. (c) ibid. 1984. 134.2338.

22. References therein: (a) Varsanyi. G. Assigmments for I Thrational Spectra of Senen Handred Benzene Dernatives John Wiley \& Sons: New York, 1974: Vol. 1. (b) Lin-Vien. D.; Colthup, N. B.; Fateley. W. G.: Grasselli. J. G. The Handbook of Infrared and Ramain Characteristic Frequencies of Organic Holecules: Academic Press: Boston. 1995.

23. (a) Gellert. R. W.: Bau. R. It Matal Ions in Biological Sustems: Sigel. H.. Ed:; Marcel Dekker: New York. 1979: Vol. 8; pp 1-55. (b) Swaminathan, V:; Sundaralingam. M. CRC Chit. Rev Biochen. 1979. 6, 245-336.

24. Speca. A. N.: Mikulski. C. M.: Iaconianni. F. T.: Pytlewski. L. L.: Karayantnis. N. M. J. horg Kucl Chem 1981. 43.2771-2779.

25. Brabec. V: Niki. K. Collect. Czech. Chem. Conmun. 1986. 51. $167-174$.

26. (a) Mikulski. C. M.: Cocco, S.; De Franco. N.: Moore, T.: Karayannis. N. M. Inong Chim. Acta 1985, 106. 89-95. (b) Mikulski. C. M.: Minutella. R.: De Franco. N.: Borges. Tr.. G.: Karayantnis. N. M. Inorg. Chim. Acta 1986. 123. 105-112.

27. Chu. G. Y. H.: Duncan. R. E.: Tobias. R. S. Horg Chem 1977. 16. $2625-2636$

28. (a) Kistenmacher, T. J.: Rossi, M.: Marzilli. L. G. Morg Chen. 1979. 18. 240-244. (b) Faggiani, R; Lippert, B; Lock. C. G.: Pfab. R. Ihorg Chem 1981. 20.2381-2386.

29. (a) Graves. B. T.: Hodgson. D. T. J. Am. Chem. Soc. 1979. 101. 5608-56(199. (b) Vicens. M.: Fiol. J. T.: Terron1. A.: Moreno. D. M. L. Inorg. Chim. Acta 1989. 157. 127-132.

30. (a) Goodgame. M.: Johns, K. W. Inorg Chm. Acta 1980 , 66. 23 27. (b) Mikulski. C. M.; Lee. C. J.: Tran. T. B.: Karayannis. N. M. 
Ihorg. Chim. Acta 1987. 136. L13-L15.

31. The major SERS bands of dI on Au nanoparticles: $230 \mathrm{~cm}^{-1}$ (Au$\mathrm{N}$ stretching). $727 \mathrm{~cm}^{-1}$ (ring breathing of py). $1042 \mathrm{~cm}^{-1}$ (Nsugar stretching). $1131 \mathrm{~cm}^{-1}$ (C-C stretching). $1318 \mathrm{~cm}^{-1}$ (C-N stretching of in). $1366 \mathrm{~cm}^{-1}$ (C-N stretching of py). $1463 \mathrm{~cm}^{-1}$ $(\mathrm{C}=\mathrm{N}$ stretching of $\mathrm{py}), 1505 \mathrm{~cm}^{-1}(\mathrm{C}=\mathrm{N}$ stretching of im). 1550 $\mathrm{cm}^{-1}$ (ring breathing), $1630 \mathrm{~cm}^{-1}(\mathrm{C}=\mathrm{O}$ stretching).

32. Reddy. P. R.: Adharani. T. K. Indian J. Chem. 1990. 29A. 1002-
1007.

33. Nelson. H. C.: Villa. T. F. J horg. Nucl Chem 1980. 42. 133-135.

34. (a) Hadjiliadis. N.: Theophanides. T. horg. Chim Acta 1976. 16. 77-88. (b) Chu. G. Y. H.: Tobias. R. S. J. Am. Chem. Soc. 1976. 98. 2541-2651. Ibid. 1978, J00,593-606

35. Fiol. J. J.: Terron. A:; Moreno. V. Inorg. Chim. Acta 1986, 125. $159-166$. 